\title{
On Determining Developmental Stages in Natural Second Language Acquisition
}

\author{
Jürgen M. Meisel \\ Universität Hamburg
}

\author{
Harald Clahsen and Manfred Pienemann \\ Universität Wuppertal
}

\section{Introduction}

Research on Second Language (L2) Acquisition, over the past ten years, has undergone substantial changes by shifting its focus of interest away from an analysis of linguistic structures alone, concentrating more on the learner himself or, rather, on the process of learning. It had become obvious that one of the major shortcomings in contrastive studies as well as in the usual kind of error analysis is that they lack thorough investigation of factors which determine the kind of approach a learner may take to acquire a second language. This again implies that it is more fruitful to study the process of learning itself instead of merely analysing its outputs. It is by now widely accepted that the learner takes an active part in the learning process and does not merely get trapped in structural gaps which linguists may find when comparing the source language (the learner's L1) and the target language (L2).

A well-documented example of this kind of problem is the case of structural interference from L1 into L2. Take for example an error one can find in the speech of Spanish or Italian learners of German: they sometimes use warum "why" when standard norms require weil "because." This is quite generally interpreted as an interference from $\mathrm{L} 1$ since Spanish and Italian do not discriminate morphologically between por qué (Sp.), perchè (It.) "why" and porque (Sp.), perchè (It.) "because." However, Felix (1977:245/6) reports the following dialogue with a 7-year old learner of German:

F: wollen wir zu Julie gehen?

G: nein

F: warum nicht?

G: warum die ist nicht hier

$$
\begin{aligned}
& \text { let's go to Julie } \\
& \text { no } \\
& \text { why not? } \\
& \text { why she is not here }
\end{aligned}
$$

There are similar uses of warum instead of weil by the same boy. What is interesting about this error is that the learner's first language is English; had it been Spanish or Italian it would have been impossible to refute the interference hypothesis. In other words, since in this case we cannot account for the use of warum, meaning "why" as well as "because," by referring to morphological identity in L1, we should look for an operation the learner might have performed when constructing and using the intermediate system which is available to him on his way to L2.

The choice of this example does not necessarily imply that we deny the possibility of interference in L2 acquisition. But it can illustrate the fact that many phenom- 
ena studied in L2 acquisition-like interference-cannot be discussed in terms of differences between linguistic structures (nor by merely classifying an error). Rather, the learning of a language must be viewed as a very complex process of which the development of a grammatical system is only one part; properties (syntactic, phonological, etc.) of L1 and L2 certainly do have some influence on this process and may account for some aspects of the learner's interlanguage. But again: other factors, especially psychological ones, are likely to be of much greater importance for our understanding of the process of $\mathrm{L} 2$ acquisition, including linguistic and non-linguistic strategies involved. This point gains further support by the observation that there exist certain similarities between L1 acquisition and L2 acquisition. To return briefly to our warum example, one should take into account that the same and similar phenomena appear in Ll acquisition. Bailey (1972:3) gives the following conversation with a 5-year old boy, David:

I came home and found the ice cream was all gone.

(David:) That's why Markey ate it all up.

Whatever reason one may find for the use of $(t$ that's $\mid$ why replacing because (we do not want to speculate on this), it will at least be a good candidate for a better explanation of the above mentioned error by Spanish and Italian learners of German.

Such an approach to the investigation of L2 acquisition-one which describes it as a sequence of approximative systems partly determined by rather general operations and strategies, some of which may even be universal-almost inevitably leads to the assumption that there exist developmental sequences which can be defined by the appearance in a strict order of certain linguistic features. This again implies that a learner acquires part of the rules in an ordered sequence-as long as his learning process is not stopped by fossilization or by some other force. This definition allows for the possibility that a rule is not acquired at all; if, however, it is learned, this hypothesis predicts when it will appear as compared to other rules ordered in this sequence. It is furthermore assumed by many authors that this order is normally the same for each individual learning a second language, more or less independently of the learner's first language.

In what follows we want to discuss the notion of 'developmental stage': how it is defined and what kind of data constitutes evidence for the appearance of a new stage in the acquisition of $\mathrm{L} 2$. We will argue that one has to distinguish between different groups of learners who may follow different paths on their way to their variety of the target language. This does not exclude the possibility that there are stages in the linguistic development of $\mathrm{L} 2$ learners which may be defined in terms of rules emerging in a predictable order. However, one will also have to allow for the possibility that within each such stage there is considerable variation. This variation, we suggest, characterizes the different learner groups linguistically; whether a learner belongs to one such group or another depends on socio-psychological factors.

Our arguments are based on data taken from informal interviews with adult Spanish, Italian, and Portuguese women and men working in Germany who did not 
receive formal instruction in German. ${ }^{1}$ These conversations with 45 foreign workers were recorded, transcribed and analyzed by the members of our research group, Zweitsprachenerwerb italienischer und spanischer Arbeiter (ZISA). ${ }^{2}$ In the following we will only deal with the acquisition of syntax although the research project is also concerned with problems of the lexicon.

\section{Determining Developmental Stages}

2.0 Leaving aside those studies which only speculate on what may constitute developmental stages in second language acquisition without much empirical basis to support these claims, one can-roughly speaking-distinguish two types of approaches. The first consists of cross-sectional studies with-generally-a fairly large number of learners analyzed; the second comprises the few existing longitudinal studies investigating the acquisition of a second language by a very limited number of learners. We believe, however, that both share one important drawback: very often variation is indiscriminately interpreted as indicating a new developmental stage. This criticism will have to be explained in detail.

\subsection{Longitudinal Studies}

As various authors have pointed out, longitudinal studies-designed according to the methods used in $\mathrm{L} 1$ acquisition-seem to be quite adequate for the study of L2 acquisition, although $L 2$ acquisition may develop less uniformly to the extent that interpersonal similarities in $\mathrm{Ll}$ acquisition can be explained as a result of biological maturation and cognitive development, whereas socio-psychological factors exert a stronger influence on the acquisition of a second language. There exist, however, only very few examples of this kind of research. One example of a study which does describe the linguistic performance of a small number of people longitudinally is the one by Cazden, et al. (1975). To our knowledge, there exist no other reports on longitudinal studies of natural L2 acquisition by adults. ${ }^{3}$ Although this kind of research has led to a number of widely accepted hypotheses about developmental sequences, it does not solve the problem of defining developmental sequences.

A longitudinal study gives a description of linguistic performance at several points of time, analyzing changes which occur between point $t_{i}$ and point $t_{i+1}$; if a linguistic feature appears systematically it is said to have been acquired by the learner. Developmental stages may then be defined in terms of acquired rules. If this is an adequate account of what makes up a longitudinal study, there are at least three major problems: time, structure, interpretation of changes. One would of course like to have only the latter as a free variable and the first two as bound. Unfortunately this is much less straightforward than one might believe at first sight.

We only want to mention briefly the last point: given a certain linguistic structure, when can we say that it has been acquired? A single occurrence would obviously not indicate that it has been acquired in the sense that the person who used it could repeat it every time a similar context occurs. This seems to indicate that we have to rely on some kind of quantification of the data. Brown (1973:258), following Cazden (1968), established as a criterion for morpheme acquisition (L1) that it must be used correctly in $90 \%$ of the obligatory contexts of three successive recordings; 
in each recording there should at least be five obligatory contexts. However, as Cazden et al. (1975:27) remarked, limitations of data sometimes make it impossible to apply this criterion in L2 acquisition:

Often, we did not find five obligatory contexts even though the subject was performing $100 \%$ correctly on a particular linguistic feature.

Brown's criterion may be more useful in L1 than in L2 research (Brown 1973); also, it seems to work better with morpheme acquisition than with word order problems.

A more serious problem with Brown's criterion is that-if applied as stated above-it ignores the insights provided by interlanguage hypothesis, since only standard-like usage is counted. Schumann (1975:35-53), for example, analyzes Alberto's (his learner's) speech in this way and comes to the conclusion that no auxiliaries (including do-support, copula, modals) can be said to be acquired, where we think one should conclude that Alberto has acquired a rather elaborate auxiliary system; but he doesn't use the correct form, e.g. supplying is where second person singular are would have been expected. Even then, Alberto does use the copula is, correctly fulfilling the requirements of Brown's criterion. In this case, Schumann as well as Cazden et al. (1975) argue that this is the result of positive transfer from Spanish. ${ }^{4}$ Similarly, Alberto is said not to have acquired past tense endings (30-33). Although this is undoubtedly the case, an interesting question might be whether he has developed means to express past tense or not. From the data quoted by Schumann, it seems as if Alberto only deletes the endings when there is an adverbial like yesterday, after ... three years, etc. This would be in accordance with some of our own findings and shouldn't come as a surprise to a creolist, since similar constructions may be found in pidgins and creole languages.

All this seems to indicate that Brown's criterion of acquisition is much less useful in $L 2$ studies than it may be for $L 1$ research. ${ }^{5}$ We believe that the most satisfying results are obtained by quantifying all features under consideration in the same fashion, indicating the number of actual occurrences relative to the total number of possible occurrences. Cazden et al. (1975) followed this procedure when studying negation and the interrogative. They showed that it allows for a description of linguistic development as well as of variation in the development, for standard-like structures as well as for features which deviate from the standard norm.

In this section we have argued that although we think that only longitudinal studies can reveal convincing evidence for developmental stages in language acquisition, such evidence does not automatically follow from an analysis of several consecutive samples of speech of the same learner. Regular or irregular intervals between a number of recordings do not guarantee either that a new stage in the linguistic development has been attained, or that one has not missed such a stage. The process of second language acquisition has to be described primarily in terms of linguistic features.

Even the most sophisticated linguistic examination of the data, however, can only reveal that changes did in fact occur. The main task then still remains to be done, namely to interpret these results. This brings us back to our remark at the begin- 
ning of this second section: so far it has always been taken for granted that all changes except certain idiosyncratic features in the developing system may be interpreted as an indication of a new step on a learner's path from zero knowledge of the target language towards the standard variety. Furthermore, it has been tacitly assumed that one may safely expect to find the same kind of development in all learners, at least with adults who share the same first language. This is a rather simplistic view of language acquisition, but it appears to serve quite generally as a guideline for research.

\subsection{Cross-Sectional Studies}

Apart from the points mentioned in 2.1., which are also valid for cross-sectional studies, we will show that these shortcomings are aggravated by certain characteristics of cross-sectional studies themselves. The procedure generally followed in such works is to analyze the linguistic performance of a number of L2 learners at a certain point of time. The results are then interpreted in one of two /similar or even identical) ways: a) either one tries to find out which areas of the grammar of the target language present most difficulties for the learner by counting the number of errors, or b/ one attempts to give the learner's distance from the standard norm in terms of grammatical complexity. The latter is normally computed on the basis of the numbers of rules acquired; this includes the possibility of special interlanguage rules which do not exist in the source and in the target language. In both cases the learners studied are then plotted on a scale which reaches from close to zero (highest score of errors, or greatest distance from the standard variety) to almost standard. As a result, different learners, or groups of learners who show comparable linguistic behavior, are then said to represent different developmental stages. Thus, cross-sectional studies which are intended to determine developmental stages in second language acquisition are necessarily based on the assumption that the process of acquisition is strictly linear and uniform.

The first question to be raised is whether one may in fact draw any conclusions about the order of acquisition from the number of mistakes. This is the working hypothesis for several cross-sectional studies although it is not always stated explicitly. The central question to be discussed here is the following one: does a high number of errors in a certain area of grammar really indicate that this structure (or rather, the set of rules which generate it) has been acquired late, and vice versa? First of all, the inherent logic does not appeal to us as imperative. There is absolutely no reason to believe that an $\mathrm{L} 2$ learner, especially in a natural setting, should always start with the "easy" parts of the grammar and leave the "most difficult" ones for later. Rather, he uses whatever is necessary to express his communicative needs, possibly choosing the least difficult of several alternatives. (This remains an open question as long as linguists and psycholinguists have great difficulties in explaining what is simple (Meisel 1980).

Therefore, a structure which shows a high risk for errors may be acquired fairly early and continued to be used deviantly until very late. On the other hand, some rules, once they are acquired, may be used correctly right from the beginning. In other words, what is discovered by research like Fathman's, analyzing the linguistic performance of "approximately 500 non-native English-speaking children 
learning English in public schools in the United States" (ages 6-14) (Fathman 1979:31), is not the order of acquisition but rather the relative difficulty of some grammatical structures of English for foreign learners. It should therefore not come as a surprise that these findings are in agreement with results reported by other researchers for different populations, but working along the same lines as Fathman. ${ }^{6}$

It is most likely that it will turn out that the two hierarchies for difficulty and for learning sequences, are not identical. The few existing longitudinal studies on L2 acquisition show that the frequency of a certain error may go up and down. Molony (1977:279), for example, reports "a dramatic increase in verb errors from three and a half months (March) to five months, then a steady decline so that by October there are almost no errors." The explanation for such development may be linguistic (e.g. structural contexts |, as well as non-linguistic; and by careful analysis one should be able to find out about this. Cross-sectional studies, however, are not likely to detect these facts, let alone to find solutions for the problem. Rather, samples taken at points of time which correspond to the end of the fifth month and sometime during the sixth moith, respectively, will probably lead to erroneous interpretations, especially if compared to errors in other areas of grammar which show a different development than the verbal constructions mentioned. This indicates, as is well known from first language acquisition research, that certain structural properties of the learner's performance can only be explained if one also knows preceding and following developments. Some features even disappear after a certain period of time and occasionally reappear later on.

These remarks should suffice to illustrate that the process of $L 2$ acquisition cannot simply be viewed as a system of an increasing number of rules. While some new rules are acquired, others are dropped after a certain period of time (specific interlanguage rules, but possibly also standard rules), and some are changed (e.g. adding more specific information to their structural description, thus restricting the range of possible applications which had been the result of overgeneralizations, as compared with the target variety.) As a consequence, grammatical complexity of one sample of a learner is a useful but not sufficient criterion to determine the developmental stage he/she has reached. Therefore, it does not seem to be admissible to plot learners on a scale, implying that the one with a "less complex" grammatical system necessarily represents an earlier stage through which the one on a higher grade of the scale should have gone. This leads to another point. Some studies apparently take it for granted that all parts of the grammar of a learner develop uniformly, i.e. if he/she progresses in one area of his grammatical competence, there must be similar developments in others. If this were not the basic assumption, one could not claim that a mean value for several groups of rules indicates an overall level of linguistic development. Not only does common logic not force us to believe in such a uniformity of development, longitudinal studies clearly show that the contrary is much more likely to happen (Felix 1976, Molony 1977). This remark should certainly not come as a surprise, since for many years language acquisition research has dealt with fossilization, and as far as we know fossilization may affect different parts of the grammar in different learners. This means that on the basis of cross-sectional studies one cannot decide, on 
principle, whether a certain structure shows 'normal' development, or whether this pattern has been fossilized just in the case of the learner under consideration.

There is a last point which we only want to mention briefly since it would take up too much space to go in to the necessary details. Although it is generally accepted that a speaker's performance does not in every respect reflect his competence (using these highly disputed terms for the sake of the discussion), there is a tendency to write a rule of grammar for each phenomenon which occurs systematically and regularly. This is especially problematic when dealing with changing systems, as in language acquisition. The linguist cannot even appeal to a "competent speaker" who, by definition, does not exist in this case.

In spite of the manifold theoretical and practical difficulties, we think that it is worth the effort to try to sort out what a person's underlying knowledge of the language must look like and how he uses this knowledge. This difference will be important as soon as the results of language acquisition studies are put into practice, e.g. in designing language classes. To give just one example: a tacit assumption shared by many researchers seems to be that a learner's performance reflects the best of his linguistic abilities. This is in conflict, however, with an otherwise equally well-known fact. Namely, someone who wants to communicate efficiently in the L 2 cannot at every instance display the best of his/her internalized grammar since it would cost too much time and effort to handle certain parts of it, the use of which is not sufficiently habitualized. Instead, the learner will be looking for convenient shortcuts.

Such shortcuts can be special production strategies. Similar to the strategies discussed by Bever (1970); Clahsen (1979) shows the usefulness of this notion in L2 studies. More pertinent to the present discussion, however, is what is generally called "simplification" of linguistic structures. Meisel (1980) suggests that one has to distinguish between at least two kinds of simplification. The first kind, elaborative simplification, serves the purpose of bringing the learner's interim grammar closer to the target norm. The second kind, restrictive simplification, reduces the grammar to make it easier for the learner to handle. Stauble (1977) argues that a third kind should be added, conformative simplification, "in which the learner simplifies his grammar by conforming to the model system and eliminating any non-standard forms."

The second kind of strategy (restrictive simplification), in particular will make the learner's speech look more deviant from the target variety of the $L 2$ than what it could actually be. Take, for example, the omission of certain syntactic categories or of morphological material. The learner 'knows' of course that there must normally be a verb in each sentence and that it carries morphological information; in his/her L1 this is quite the same, and one hardly finds a learner who consequently deletes all verbs, and not many always use the infinitive. But deletions of this kind make it easier to use the grammar; they help to avoid the choice of the right position of the verb and the correct inflectional ending.

If our interpretation of this kind of simplification is correct, the linguist who wishes to write a transitional grammar has to try to differentiate between what the 
learner has not yet acquired and what he/she is not yet able to use correctly in every context. Otherwise one cannot achieve psychological plausibility for the grammar which seems necessary for an adequate explanation of a learning process, be it linguistic or other.

The problem of this section-to discover what is part of the internalized grammar of a L2 learner-has to be solved by longitudinal studies as well as by crosssectional studies. The former, however, have the advantage of being able to study one person's speech at different points of time and possibly at different places and in different contexts. This may help to discover which strategies are applied by the learner.

We have tried above to show that cross-sectional studies, in addition to difficulties mentioned in 2.1., have to cope with certain problems which make it rather unlikely that they could be an adequate way to discover developmental stages in $\mathrm{L} 2$ acquisition. Depending on methodological choices, some problems become more, others less important. Works which attempt to describe L2 acquisition by writing transitional grammars have serious difficulties with the point mentioned last. On the other hand, they can avoid comparing the learner's speech with the norm of the target variety-the latter being hard to define in precise terms anyway. This again is a major shortcoming of studies which measure the learner's achievements by counting the relative frequency of errors. One risks violating the interlanguage hypothesis completely; at least a difference should be made between a) what has been acquired according to the standard norm, b) progress which does not reach the norm, c) nothing acquired at all. Dulay and Burt $(1973,1974)$ try to take this into account:

no functor supplied

misformed functor supplied

correct functor supplied

$$
\begin{aligned}
& =0 \quad \text { (she's dance) } \\
& =0.5 \text { (she's dances) }
\end{aligned}
$$$$
=1.0 \text { (she's dancing } \mid
$$

The same procedure is followed by Bailey, Madden, and Krashen (1974). These authors are, furthermore, aware of the fact that difficulty ordering is not identical to the sequence of acquisition.

One obvious possibility of combining the advantage of a cross-sectional study with at least some of the strong points of longitudinal research is to see all or a few of the consultants a second time after a certain period of time. There is the danger, however, of combining the shortcomings of both methods instead of the advantages, for the number of learners has to be reduced, and at the same time one does not get the same number of samples from each person.

Hyltenstam (1977), on the other hand, seems to have used this technique quite successfully. He tested 160 subjects on two occasions. At time 1 they had studied Swedish for three weeks; time 2 was five weeks later, and 160 persons participated on both occasions. But again, one has to pay a high price. Hyltenstam could not record natural conversations, but had to use a highly structured test to be able to handle this amount of data: learners "were required to choose one of two marked 
spaces in which to place negation" (386). This does, of course, not leave any room for a creative use of an interim grammar.

To sum up, we believe that the only promising way to find out about developmental sequences in natural L2 acquisition-and possibly in language acquisition research quite generally-is to study the process of language acquisition over a longer period of time. The results should then be backed up by crosssectional studies. This procedure will certainly not eliminate automatically all problems discussed in this second section of our paper, but it will at least help to come to grips with them.

\section{A multi-dimensional model of second language acquisition}

3.0. In sections 2.1. and 2.2. we have tried to explain our remark that cross-sectional studies as well as longitudinal investigations both share one important drawback: researchers tend to interpret all systematic variation as indicating a new developmental stage. Part of our criticism was concerned with methodological problems which will not be pursued any further in this paper. Our main point, however, is that second language acquisition is quite generally viewed as a linear process, as a straight line leading from zero to the target variety of $L 2$. Systematic differences between the interlanguages of either different learners or of the same learner at different points of time are indiscriminately said to constitute evidence for his/her progress along this line toward L2. As far as we can see, for crosssectional studies it is difficult to avoid this uniformity hypothesis about L2 acquisition; this is why we think they cannot furnish conclusive evidence for ordered sequences of rules. Viewing language acquisition as a linear and uniform process does not allow one to attribute different degrees of importance to different structural properties of the learner's speech, either on language internal or on social or psychological grounds. For the social scientist this is a rather implausible assumption in the case of second language acquisition and calls for further investigation.

3.1. Works by E. Haugen (1956), Gardner and Lambert (1972), Gardner et al. (1974), Schumann (1975) and others, as well as our own studies (compare footnote 2), indicate that socio-psychological factors play a prominent role in second language acquisition. Social distance from the target group, intensity of contact, attitudes, motivation, etc. have been shown to be more influential than, e.g. duration of stay, intelligence, etc. If it is widely accepted that such factors do influence second language acquisition, one will nevertheless find that for the most part this influence is merely postulated in rather general terms. It remains to be seen to what extent and in what way it works.

A very useful discussion of the problems of language use in bilingual communities is presented by Einar Haugen in his book Bilingualism in the Americas, which contains many more stimulating thoughts about the topic. He distinguishes between "two social functions of language: 1) Communication and 2) Social identification." This is in itself not new, and similar suggestions have been made many times in the history of linguistics. What seems interesting to us is the consequence Haugen (1956:96f) shows to exist for the acquisition of the second language: 
Mere communication may be satistied by a relatively modest mastery of the second language; social identification with a dominant group may require something approaching native command.

A similar distinction is made by Gardner and Lambert (1972:3), who stress the fact that there is a close connection between acculturation and language leaming success. They write:

The learner's ethnocentric tendencies and his attitudes toward the members of the other group are believed to determine how successful he will be, relatively, in learning the new language. His motivation to learn is thought to be determined by his attitudes toward the other group in particular and toward foreign people in general and by his orientation toward the learning task itself. The orientation is said to be instrumental in form if the purposes of language study reflect the more utilitarian value of linguistic achievement, such as getting ahead in one's occupation. In contrast, the orientation is integrative if the student wishes to learn more about the other cultural community because he is interested in it in an openminded way, to the point of eventually being accepted as a member of that other group.

The works of Gardner and Lambert concentrate on language learning in a school setting. We believe, however, that intended integration for social identification with the host community) is of an even greater importance in the case of natural second language acquisition by ethnic minorities, especially if they immigrated recently, and we will test this hypothesis by using it as a starting point in explaining $\mathrm{L} 2$ acquisition by foreign workers in Germany.

Schumann (1975) also stresses the importance of social and psychological factors in natural second language acquisition as well as in second language learning. Continuing the thoughts of Gardner and Lambert (1972) and of Gardner et al. (1974) he further elaborates on the role of affective factors and of social distance in second language acquisition. He argues, for example, that social distance will make it difficult for the learner to acquire the language of the target language group and lists eight factors "that promote either social distance or proximity between two groups and thus affect the degree to which a second language learning group acquires the language of a particular target language group." (Schumann 1976:1).

Although the works just mentioned do certainly help to attain a better understanding of the influence of socio-psychological factors on L2 acquisition, we think that critics are basically right when they remark that all this is still much too vague. Still, it would be unfair to expect detailed information about which non-linguistic factor influences the development of which linguistic feature and in which way. In the first place, it does not appear to be a reasonable hypothesis to predict such one-to-one relations. Reality will probably prove to be far more complex; one must be prepared to find a network of interrelations between linguistic and nonlinguistic features. Furthermore, much more research is needed in this area. We do think, however, that one must go beyond general statements about the possible influence of socio-psychological facts on linguistic development, and we hope to be able to take an important step in this direction by combining the concepts of "variation" and "developmental sequences." 
It is quite a remarkable fact that even those researchers who underline the importance of socio-psychological factors seem to view second language acquisition as a linear process. According to this position, social distance, attitudes, etc. only determine the degree to which the second language is acquired. In what follows we will argue that the uniformity hypothesis has to be abandoned in favor of a theory which sees $L 2$ acquisition as a multi-dimensional process. This does not conflict with the view of $L 2$ acquisition as a sequence of ordered developmental stages. But within each stage one will have to allow for considerable variation. We suggest that this variation be explained by the existence of different learner groups which result from socio-psychological differences. Attitudes and motivation, as described by Haugen and the other scholars mentioned above, will probably play the most important role. In other words, they do not merely determine the degree to which a second language is acquired but also the kind of transitional system the learner acquires, e.g. as a result of certain strategies of simplification.

In the course of this paper we repeatedly criticized the fact that the uniformity approach did not allow one to attribute different degrees of importance to different structural properties, since it interprets all systematic variation as indicating new developmental stages. A brief discussion of the use of the copula by L2 learners may serve to show that it is necessary to distinguish between those features which may in fact be said to represent a step forward toward the target variety of $L 2$, and others which are peculiar to different learner varieties but may occur at the same developmental stage.

Several studies on early stages of L2 acquisition point to the early appearance of equational constructions. Felix (1976) even claims that they are characteristic of the very first stage, preceding auxiliaries and main verbs. As has also been noted by a number of scholars, the internal structure of equational constructions varies: sometimes the copula is omitted, sometimes it does appear, as required in standard German as well as in English. The question now arises as to whether the use of the copula indicates a new developmental stage or not. Felix (1976:73f) briefly discusses this problem, but he cannot find conclusive evidence to settle it.

As mentioned before, in section 2.2., we distinguish between different kinds of simplification strategies, as proposed by Meisel (1980) and Stauble (1977). But unlike Stauble, we do not believe that the process of $\mathrm{L} 2$ acquisition can be described as a continuum passing from basilang (using restrictive simplification) through mesolang (use of elaborative simplification) toward acrolang (use of conformative simplification). The terms basilang, mesolang and acrolang refer to different stages of $\mathrm{L} 2$ acquisition and coincide with the terms basilect, mesolect and acrolect, which are familiar from creole studies. This idea of a continuum may prove to be very useful in L2 studies, but again, one cannot represent L2 acquisition as a straight line. Stauble [1977:24\} claims "that second language learning in a natural environment may be seen as an aspect of the general process of cultural adaptation." This, however, is only half of the truth as we tried to show above, referring to Haugen and others. In other words, if learners can be grouped according to various kinds of orientations- "instrumental" versus "integrative" in terms of Gardner and Lambert-then one must be prepared to find that some learners will never go 
beyond a certain point during the process of cultural adaptation. This does not necessarily imply that the process of $\mathrm{L} 2$ acquisition comes to an halt at the same time. Learners may very well continue to acquire new rules of the $\mathrm{L} 2$ grammar, i.e. they will reach new developmental stages. But they may stick to certain kinds of simplification (i.e. restrictive simplification), which other learners, on the other hand, may never use-not even in very early stages. This is to say that although pidginization is found very frequently in early stages of L2 acquisition, it is not necessarily present in all learners and it may not be abandoned by all those who do use it. Note that Stauble (1977:14) reports that one of her subjects, Juan, "did not exhibit a basilang phase in his negation development."

Returning to the problem of the missing copula in equational constructions, we suggest that the use of the copula is not an indication of a learner's new developmental stage but has to be explained by the strategies of the group he/she belongs to. This implies that, as a learner progresses in his/her L2 development he/she may continue not to use the copula. Only a change of strategies of language acquisition and language use - possibly caused by a change in orientation - is likely to stimulate changes in the use of such linguistic material. Note that this may cause the first appearance of certain features which had not been present so far; it may also cause a higher frequency of use since, in many cases, omission of linguistic material is not total.

Our hypothesis about the use of the copula is confirmed by the results of the longitudinal study administered by $M$. Pienemann (1979b). Preliminary results are reported in Pienemann (1979a). He studied the acquisition of German by two nine-year old Italian children over a period of approximately one year; these children attended an Italian "preparatory class" where the normal means of instruction is Italian, and German is taught five hours per week. Over a period of six months, both girls used almost exclusively one-constituent-utterances (NP or V); then $N P+V(N P)(P P)$ utterances appeared. At this point, differences between Luigina and Concetta became apparent. Luigina systematically deleted the verb if there was an object-NP to follow, thus producing either $N P+V$ or $N P+O+N P(N P)$ patterns. Concetta, on the other hand, almost never (e.g. once out of 40 utterances) deleted a verbal element. As soon as equational constructions appear, Concetta uses the copula; she says for example:

de Kinder essen Apfel

Deutsch is gut

the children eat apple

German is good

Luigina also uses equational constructions but she deletes the copula; examples from her speech are:

ein Mädchen $\varnothing$ bier a girl (drink) beer

ich $\varnothing$ Mädchen

I (be) girl

Apart from this, both girls develop their knowledge of German in the same way, i.e. their utterances contain the same constituents and are equally complex in number of constituents. What is even more interesting is that during the following months, Luigina still deleted verbal elements, as can be seen from Table 1: 
Table (1)

\begin{tabular}{|c|c|c|c|c|c|c|c|c|c|c|c|c|}
\hline Interview No: & 6 & 7 & 8 & 9 & 10 & 11 & 12 & 13 & 14 & 15 & 16 & 17 \\
\hline $\begin{array}{l}\mathrm{V} \text { missing in } \\
\text { specified } \\
\text { contexts }\end{array}$ & 1. & (1.) & 1. & (1.) & 0.5 & $\mathbf{x}$ & (1.) & $|0.5|$ & 1. & 1. & $\mathbf{x}$ & 0.4 \\
\hline $\begin{array}{l}\text { copula } \\
\text { deletion }\end{array}$ & 1. & $\{0.67\}$ & $\mathrm{x}$ & 0.75 & 1. & $(1)$. & $(1)$. & (1.) & $(1)$. & 0.91 & 0.5 & 0.13 \\
\hline $\begin{array}{l}\text { Total of } \\
\mathrm{V} \text { deletion }\end{array}$ & 0.8 & 0.5 & 0.57 & 0.44 & 0.5 & (1.) & (1.) & 0.4 & 1. & 0.79 & 0.44 & 0.23 \\
\hline
\end{tabular}

Luigina: missing verbal elements

Note: $x$ : no relevant data available

( ): only very limited amount of data available

The first line gives the probability of deletion for main verbs in such contexts where the verb is predictable: haben, bekommen ("have," "receive") + NP, locative be + adverbial, verbs of movement + directional adverbial, verb + particle. The second line shows the probability of copula deletion. The last line indicates the probability of deletion for all verbs. (Always calculated: in terms of deletions/possible occurrences.)

The table shows that Luigina does not give up the deletion of verbal constituents over a long period of time. At Time 6 , for instance, all copulas and almost all other verbal elements are deleted. Although the total number goes down at certain times, there does not seem to be a continuous development, at least until Time 15. A change may be coming up at Time 16. But so far, although there was linguistic development in other areas, copula deletion occurred very frequently; the same is true for the deletion of main verbs in the contexts mentioned above. We interpret both kinds of deletions as instances of restrictive simplification which is applied to minimize processing efforts when using the foreign language. Communication is not severely hindered by these deletions since the missing elements can easily be filled in these contexts, e.g.

meine Mutter $\emptyset$ Italien, Vater $\emptyset$ Deutschland. Arbeit.

my mother Italy, father Germany. work.

This kind of pidginization can very well be used as long as the learner is merely interested in getting his message across. It is interesting to look at Heidelberger Forschungsprojekt 'Pidgin-Deutsch' HPD (1976) for this matter.

They group 48 learners on the basis of a syntactic index which indicates how elaborate the grammatical system of a learner is. Then they arbitrarily divide the whole group into four subgroups and claim that these represent different developmental stages of L2 acquisition, e.g. HPD (1976:178). They find that Group I ("least developed") and Group IV ("highly developed") represent two stages which can clearly be differentiated. Differences between Groups II and III are minimal. 
This result certainly does not come as a surprise, for the learners have been ordered according to the complexity of their utterances; if one compares the extreme ends of this continuum, they necessarily differ in many respects and Group I must be more 'pidginized' than Group IV. But does this reflect the order of acquisition of certain rules, as is claimed by HPD $(1976: 157)$ ? Without repeating the criticism put forth in Section 2., we nevertheless want to argue against this conclusion, using the example of main verb deletion and copula deletion.

As for verb deletion, HPD (1976:157f) claim that the appearance of the verb is a major indication of syntactic development. In many respects this assertion is trivial; but still, the four groups do not represent developmental stages. The probability of verb use for these groups is given as I: .41, II: .70, III: .77, IV: .96. As for the use of the copula, HPD (1976:224) give the following figures: I: .03, II: .04, III: .14, IV: .22. The first figures (verb use) refer to all verbal elements: main verbs, auxiliaries, modals, and copula. In other words, Group I uses one of these with a probability of 41 , or-as we would say-the total of deletions of verbal elements is .59. The figures for the copula indicate the probability of a copula appearing if there is a verbal element; these figures do not refer to the total of possible appearances. Based on our arguments in Section 2, supported by the data quoted from the longitudinal study, we suggest that the findings of HPD (1976) need not be interpreted as evidence for a sudden increase in the use of verbal elements from Stage I to Stage II; nor does it show a similar development in the acquisition of the copula between Stage II and Stage III. Rather, the more frequent use of the corresponding rules by speakers of Group IV may be an indication of differences in social distance, etc. This is supported by the observation of HPD (1976:334 f, $348 \mathrm{ff}$ ) that those in Group I have little contact with Germans at work and virtually no contact with Germans after working hours. Thus, the work by HPD (1976) is good evidence that such factors influence quite strongly the success of natural L2 acquisition. But it gives no support to the claim that the interlanguage of Group I is an early stage through which those in IV must have gone.

3.2.0. This brings us back to the problem stated above: we have tried to explain what is meant by making a difference between developmental stages and variation within stages, according to learner groups of different orientations. The use of verbal elements and especially the use of the copula served as an illustration. We also tried to show that limited success in L2 acquisition need not be interpreted as an early stage but may very well be one possible variety of the learners' interlanguage. But we are still left with the problem of defining the criteria with which one could distinguish between features which mark a new step toward the target norm of $\mathrm{L} 2$ and others which are characteristic of different learner varieties.

As has been mentioned before in referring to Stauble (1977), it is most likely that some features of pidginization may be used in early stages by many if not by all learners. Thus, a clearcut distinction does not seem to be adequate. Nevertheless, we believe to have given sound reasons for making this difference in spite of certain fuzzy areas. The problem will only be solved in a satisfactory manner by longitudinal studies; the results from Pienemann (1979a) are very encouraging in this respect and seem to constitute strong evidence in favor of our hypothesis about multi-dimensional processes in $\mathrm{L} 2$ acquisition. 
For the time being, however, one must also look into cross-sectional studies in search of criteria to identify features marking linguistic development. One way to do this is to analyze the speech of learners who for various independent reasons may be classified as rather advanced or retarded in the process of L2 acquisition. By comparing the features they have in common and those in which they differ one may form hypotheses about the problem we are concerned with. Still, these assumptions have to be tested by longitudinal studies and may finally turn out not to be correct. Being aware of the problems outlined in Section 2 will certainly help to avoid certain pitfalls, but they are no guarantee of infallibility.

An additional criterion for identifying those features which indicate new developmental stages is the assumption that it should be possible to plot such features on an implicational scale. This is a natural consequence of the idea on which most language acquisition studies are based, namely that certain rules are acquired in a strict order. If this is correct, rules may be ordered in the following way:

$$
R_{n} \supset R_{n-1} \supset \ldots R_{i}
$$

That is, if a learner has acquired rule $R_{n}$, he has also acquired $R_{n-1}$ and so forth, down to $R_{i}$. But the one who has acquired $R_{n-1}$ does not have $R_{n}$. What speaks in favor of implicational ordering is not only that it is in accordance with common practice of language acquisition research but, as Bailey $(1976,1977)$ convincingly argues, it constitutes a psychologically plausible hypothesis about what is learnable. In other words, if we find that all learners of $L 2$ who have acquired rule $R_{3}$ also possess rules $R_{2}$ and $R_{1}$, but those who do not yet have $R_{2}$ do not use $R_{3}$ either, then we may assume that the three rules are ordered as

$$
R_{3} \supset R_{2} \supset R_{1}
$$

and we can furthermore hypothesize that each of these rules marks a new developmental stage.

In the following we will first give an example of three such rules which, according to our hypothesis, mark developmental stages and can be said to be implicationally related; then we will show variation within each of the stages thus defined. This discussion is based on the analysis of data obtained from six Spanish and Italian learners, focusing on questions of word order related to verbal elements.

3.2.1. A central problem of German word order is the position of the verbal elements, especially if they occur in sentence final position. Without further mentioning the numerous problems concerning underlying word order and the derivation of surface order, we will assume that underlying S-V-O order is an adequate working hypothesis for a grammatical description of the acquisition of German as a second language by speakers of Italian, Portuguese and Spanish. For a detailed discussion of these topics we want to refer to Meisel and Pam (1979).

As is well known, German requires sentence final surface position of the verb in certain embedded constructions. Furthermore, particles-like in (2)-and those verbal elements which do not carry tense and/or modality markers /henceforth 
called "non-inflected verbs") appear at the end of embedded as well as of nonembedded sentences. Pam (1979) suggests that in both last mentioned cases-exemplified in (1) and (2)-a single rule can be used to move the verbal element into the required positon:

(1) ich habe ein Haus gebaut

(2) Fritz sieht das Bild an

I have built a house

Fritz looks at the picture

We will follow this suggestion; but unlike Pam (1979) we will distinguish this operation from a different one which moves the inflected verb to the end of an embedded sentence. The reasons for distinguishing two movement rules for the verb are explained in some detail in Clahsen and Meisel (1980).

As a result, we postulate the following rules: $V \rightarrow$ END and PARTICLE. $V \rightarrow$ END applies

- after subordinating conjunctions (Comp)

- in indirect interrogative constructions (WH)

- in relative clauses (Rel)

The structural description of PARTICLE is met if the VP contains

- a modal (Mod) and a main verb (V): Mod $+\mathrm{V}$

- an auxiliary (Aux) and a past participle: Aux + V+Part

- a particle $(P)$ and a verb: $P+V$

- a complex verb group including a particle: $A u x+P+V+$ Part

The third rule we want to take into consideration is (subject-verb-) INVERSION which is obligatory in German

- after an interrogative pronoun (WH) as in (3)

- after the preposing of an adverbial, as in (4)

- after topicalization either of a simple NP as in $(5)$

$(=$ TOPI 1$)$ or of an embedded clause as in $(6)$

(= TOPI 2$)$.

(3) wann gehst du nach Hause?

(4) jetzt gehe ich nach Hause

(5) diesen Tabak kaufe ich

(6) wenn ich nach Hause gehe, kaufe ich diesen Tabak.

when do you go home?

now I go home

this tobacco I buy

when I go home, I buy this

tobacco

Our analysis of the data obtained from more than 40 adult learners reveals that the three rules may be said to be implicationally related in the sense that learners who have acquired $\mathrm{V} \rightarrow \mathrm{END}$ also possess the other two rules; but some learners who have acquired INVERSION do not apply $V \rightarrow$ END, although they have PARTICLE; a third group of learners only has PARTICLE but not the other two rules. We have not found a single person who has acquired $V \rightarrow$ END but never uses the other two movement rules. If our hypotheses are correct, one may assume that there are four developmental stages which can be defined by means of these rules:

I: none of the three rules has been acquired

II: only PARTICLE has been acquired

III: PARTICLE and INVERSION have been acquired

IV: PARTICLE, INVERSION and $\mathrm{V} \rightarrow$ END have been acquired 


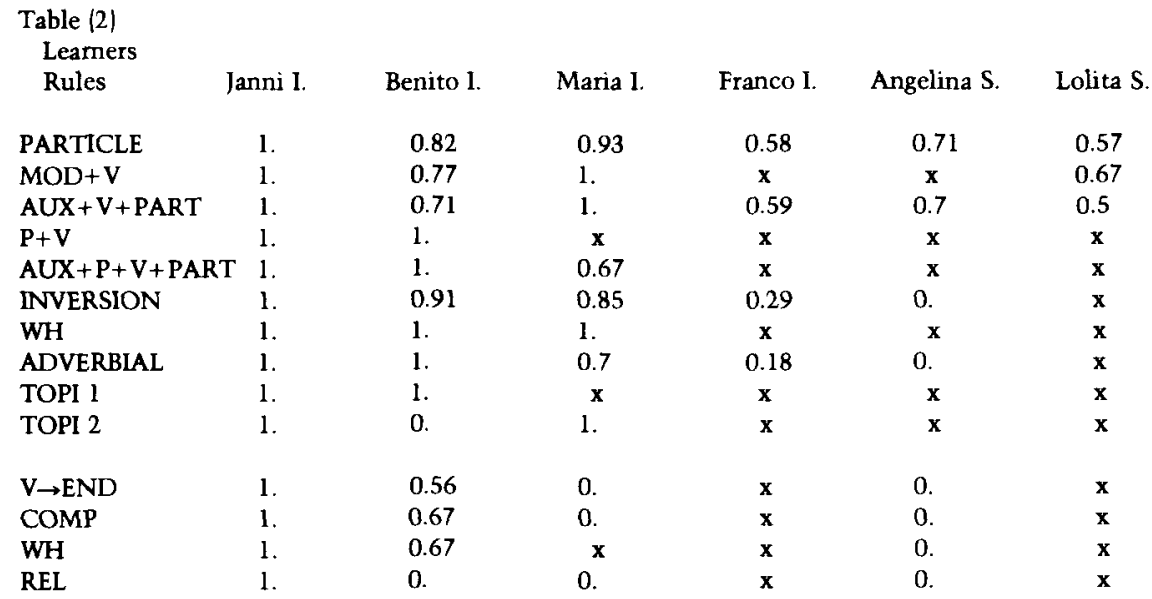

\section{Word Order Rules}

Table (2) should illustrate what has been said so far. We have chosen six persons representing these assumed stages: II (Lolita S. and Angelina S.), III (Franco I. and Maria I.) and IV (Benito I. and Janni I.). The " $X$ 's" indicate that no relevant data are available. Either structural contexts which would make the application of the rule necessary are avoided (see below for further remarks on avoidance strategies), or there are less than four possible contexts. A " 0 ," on the other hand, indicates that the contexts for the rule application are present (e.g. there are preposed adverbials, relative clauses, etc.), but the rule is not applied.

Note that this ordering of the three rules is by no means trivial. Intuitively, one might have expected INVERSION to be learned first since it also exists in Spanish and Italian, at least in certain structural contexts. Furthermore, one may be surprised by the fact that PARTICLE and V $\rightarrow$ END differ so much with respect to the order of learning, for the structural changes of both rules seem to be quite similar. We do not further go into this problem, but rather content ourselves with the observation that this ordering seems to be well established; see Clahsen (1980) for an attempt to explain why this is so.

3.2.2. In sum, we conclude from these observations that the position of the verb in constructions like the ones mentioned is a reliable indication of the developmental stage attained by the learner. It goes without saying that the placement of the verb alone is not a sufficient criterion, although it may be a necessary one. Taking this conclusion for granted, one can now show that within the thus defined developmental stages, there is a considerable amount of variation.

The first argument is based on the same verb position facts as above; a closer look at the rules reveals important differences. Within what has been called Stage II one can see that Lolita S. avoids (or does not yet have-this depends on the interpretation of the facts/contexts which would make the movement of the verb necessary; Angelina, on the other hand, does have the necessary contexts, but she cannot yet 
(does not yet) apply the rules. Similarly, within Stage III, Franco I. shows X's, whereas Maria I. has some 0's.

What is more important is that learners may reach a new developmental stage without being able to use the rules acquired before in all possible contexts. Table 2 shows, for instance, that Benito I. (Stage IV) who uses V $\rightarrow$ END quite frequently, does not invert subject and verb after topicalization of embedded clauses, although he does have quite a number of such topicalizations. Maria I., on the other hand, who does not yet have $V \rightarrow E N D$ applies the two other rules in all contexts. She also applies PARTICLE in P+V constructions and INVERSION after TOPI 1 ; the X's are due to the low frequency (below 4) of these constructions.

In other words, we believe we have found a phenomenon similar to the deletion of the copula. Whereas some learners seem to acquire a rule perfectly before they move on to the next learning task, others are less perfect in terms of the target language. They may, however, be more efficient in communication. Note that Benito I. has a great number of topicalizations which may be classified as a rather sophisticated stylistic means, but without TOPI 2 his grammatical score would be l. = standard norm. At any rate, Benito's example shows that a learner can reach new stages without having acquired other rules for all possible contexts. Another observation-similar but not identical to this one-is that the different contexts of rule applications are not implicationally related in terms of probability of application. That is, from table $(2)$ one cannot conclude that a given rule will first be applied for one specific context, then for the next (possibly the more complex one), and so on. Learners differ greatly with respect to which context is most suitable for the application of a new rule.

Table (3)

\begin{tabular}{|c|ccc|}
\hline STAGE IV & Janni I. & Benito I. & \\
& 0.07 & 0.16 & \\
& 0. & 0.08 & \\
& 0. & 0.26 & Franco I. \\
STAGE III & Maria I. & & 0.35 \\
& 0.18 & & 0.53 \\
& 0. & & 0.5 \\
\hline STAGE II & 0.11 & Angelina S. & Lolita S. \\
& & 0.32 & 0.62 \\
& & 0.25 & 0.7 \\
& & 0.47 & 0.67 \\
\hline
\end{tabular}

Missing Elements

Note: First figure: deletion of subject pronouns

Second figure: deletion of copulas

Third figure: deletion to avoid application of movement rules. 
The second argument is based on deletion phenomena. Table 3 shows the probability of deletion for certain syntactic categories. The first observation is that certain elements are more likely not to be used at an early stage of $\mathrm{L} 2$ acquisition than at a later stage. This may be rather trivial, although it will be shown not to be a necessary assumption. For we have also grouped the six learners-tentativelyaccording to whether they use more or fewer strategies of simplification, as explained in preceding sections of this paper. Those toward the right represent more simplified learner varieties, those to the left are more 'grammatical' learners in terms of the standard norms. This grouping, although based on the frequency of deletions, is in accordance with what has been said in the preceding paragraph. That is, Benito I., who is said to have reached Stage IV without using the rules in all possible contexts, is plotted more towards the right (more simplified variety) than Maria I., who is only on Stage III but uses those rules in more contexts than Benito and also differs with respect to missing elements. Note that from what has been said before about the different kinds of simplification, it may be expected that at an early stage of L2 acquisition (almost?) all learners will use some kind of simplification. This is why there is an empty space on the lower left of Table 3; it may of course be filled by those speakers who, right from the beginning, follow very closely standard norms. On the other hand, we would suspect that the blank on the upper right of Table 3 is less likely to be filled since those learners who use restrictive simplification are the same who we would expect to fossilize at a rather early point of time. We make this assumption because we think that the same sociopsychological factors lead to restrictive simplification as well as to fossilization.

We have given three figures for each learner, indicating how often an element is missing, computed on the total number of possible occurrences $\mid=$ actual occurrences + number of omissions). The first figure refers to missing subject pronouns; the second refers to missing copulas. However, as has been pointed out repeatedly, there may be different reasons for omitting an element in one's utterances. This is why we gave Figure Three, indicating those deletions which make the application of a movement rule unnecessary. As far as the three rules mentioned before are concerned, one might list:

PARTICLE: V or object-NP, i.e. elements over which one has to move INVERSION: subject or verb, i.e. one of the categories to be inverted $\mathrm{V} \rightarrow$ END: $\mathrm{V}$ or those elements over which it would have been moved

This kind of deletion, which we interpret as an avoidance strategy, shows the most striking differences at Stage IV, comparing Janni I. and Benito I. Looking at the data for Maria is quite interesting; she seems to be a good example for what we have called multi-dimensional L2-acquisition. Being on Stage III, toward the far left $1=$ few restrictive simplifications|, she deletes less frequently than Franco, who is located on the same stage but farther to the right (pidginized variety). She furthermore deletes more frequently than Janni I., who is on the next stage and within the same right-left grouping, but - what is more interesting - she deletes less frequently than Benito I., who is more advanced than she-but who is in a different group, more to the right. The same is true for Angelina S., as compared to Lolita S. (same stage, different grouping) and Franco I. (next stage but different grouping). 
A third argument in favor of learner grouping within different stages will only be mentioned briefly; it is explained in more detail in Clahsen (1980). Comparing the utterances of Maria I. and Franco I. one can see that Franco only uses INVERSION if the application of this rule does not result in a surface structure where the verb and its complement are separated by another element. If, however, INVERSION would move the subject between the verb and its complement, he either deletes the subject or he does not invert:

(1) und dann ich hab gemacht meine Kinder

(2) und dann hab $\varnothing$ meine Kollega gesprochen

and then I have made my children $=$ no inversion

and then $\varnothing$ have spoken with my colleague

Clahsen argues that there are certain strategies which avoid the interruption of verb + complement sequences thus keeping down the cognitive cost of language production. Franco I. uses such strategies, whereas Maria I., who has reached the same stage as Franco, does not. As noted above these strategies may help to explain why certain structures appear in a given order and why some speakers differ from others although they can be said to have attained the same developmental stage.

3.3. In the preceding sections we have explained what we mean by a multidimensional model of second language acquisition, and we have given illustrative examples from the linguistic analysis. It seems to us that the difference between developmental stages and learner groups is well established on the basis of linguistic facts. As pointed out above, the next steps in the analysis would be to group the learners on the basis of an evaluation of their socio-psychological background, and then to relate the two groupings.

In the present paper we can only mention these problems very briefly. For more details we have to refer to our forthcoming project report (compare footnote 2). The crucial problem is to determine how socio-psychological factors-which add a new, third, dimension to the model of L2-acquisition-influence a learner's position in the two other dimensions: development towards the target variety and use of a more or less restricted variety within each stage. As a working hypothesis, we adopt an approach similar to that of Haugen (1956) and the other scholars mentioned in 3.1. We must keep in mind, however, that it is not only a question of "sooner or later":

the need to communicate functional information, by the most efficient means available, exerts an initial pull towards an optimal state of simplification ... Only later, more complex needs (functional and/or social) motivate internally the recomplexification of the system. For many learners, however, such complex needs may never arise. (Littlewood 1975:3)

It may even be more important to find out which factors are responsible for the pull towards that kind of simplification which speakers adhere to even as they go through different developmental stages.

To find out about this, we selected for each learner 35 items of information out of the total knowledge (105 items) about his/her social background. These questions assemble facts which are judged as possibly being relevant for the forming of attitudes and motivation; they refer to origin, education, job activities, contact with Germans and with other foreigners, neighborhood, family relations, activities after working hours, use of mass media, language choice, etc. Each item is weighted 
on a scale from 1 to 3. If, for example, a person never meets a German after working hours, the relevant item will be marked 1; if he/she only reads German papers, this will be marked 3 . The results of this study have been analyzed by means of a computerized factor analysis, looking for those factors which contribute most significantly to the forming of learner groups when matched against the groups which have been formed on the basis of language internal criteria. The validity of the grouping was tested by using a discriminant analysis. The results are furthermore checked against each learner's integrative motivation. This again is established by means of an evaluative assertion analysis which has been worked out by our research group (Clahsen and Pienemann 1978) adapting the analysis proposed by Osgood et al. (1957) to our needs.

All this will contribute to a better understanding, we hope, of what has been called the "orientation" of a learner. It should at least be plausible, by now, that different orientations not only determine the degree to which a learner can approach the target variety in terms of developmental stages, but also the kind of variety he/she uses within each stage. We would like to add, however, that preliminary results of our study on the social background of the learners, and of the evaluative assertion analysis make us hesitate to accept the terminology of Haugen (1956) or of Gardner and Lambert (1972). Instrumental as well as integrative orientations can lead to successful language acquisition, as Gardner and Lambert have themselves pointed out. The relevant difference which we have found as a result of our analyses is whether a learner's orientation is segregative or whether he can hope that an integrative orientation might be successful. In this sense, integration need not mean complete identification with German society. Such an extreme case of identification leads to the loss of ethnic identity and to assimilation to German society. For the acquisition of German as a second language this is probably the best solution, but certainly not for the person who seeks a balance between the two conflicting social value systems. There are, on the other hand, very successful learners who stress their ethnic identity and do not want to identify by any means with German values, except for their job. This kind of instrumental orientation which aims at what may be called "instrumental integration" apparently leads in some cases to the same linguistic results as assimilation. We thus view both as extreme cases of an integrative orientation, as opposed to segregative orientation. The latter may result either from a lack of interest in contact with Germans beyond-possibly non-verbal-cooperation at work; more often it results from discrimination on the part of the German population, and/or the foreigner not seeing any chance to be successful in achieving adequate compensation for his/her efforts, either professionally, or socially or linguistically.

In sum, we view the socio-psychological factors as forming a continuum with a segregative orientation at its one extreme and an integrative orientation at the other. As always, both extremes are the least probable cases. Most likely, each person will have to be plotted somewhere in between. The factor analysis mentioned above attempts to do just this: determine the position of a person on this continuum. Matching the results against the outcome of the linguistic analysis, one can attempt to answer the question of section 3.1. concerning the role of socio-psychological factors on the process of natural second language acquisition. 
Before one can go into this "third dimension," however, one must first get a clear picture of the two other, language internal ones. The following simple figure should help to illustrate what has been said so far:

Figure (1)

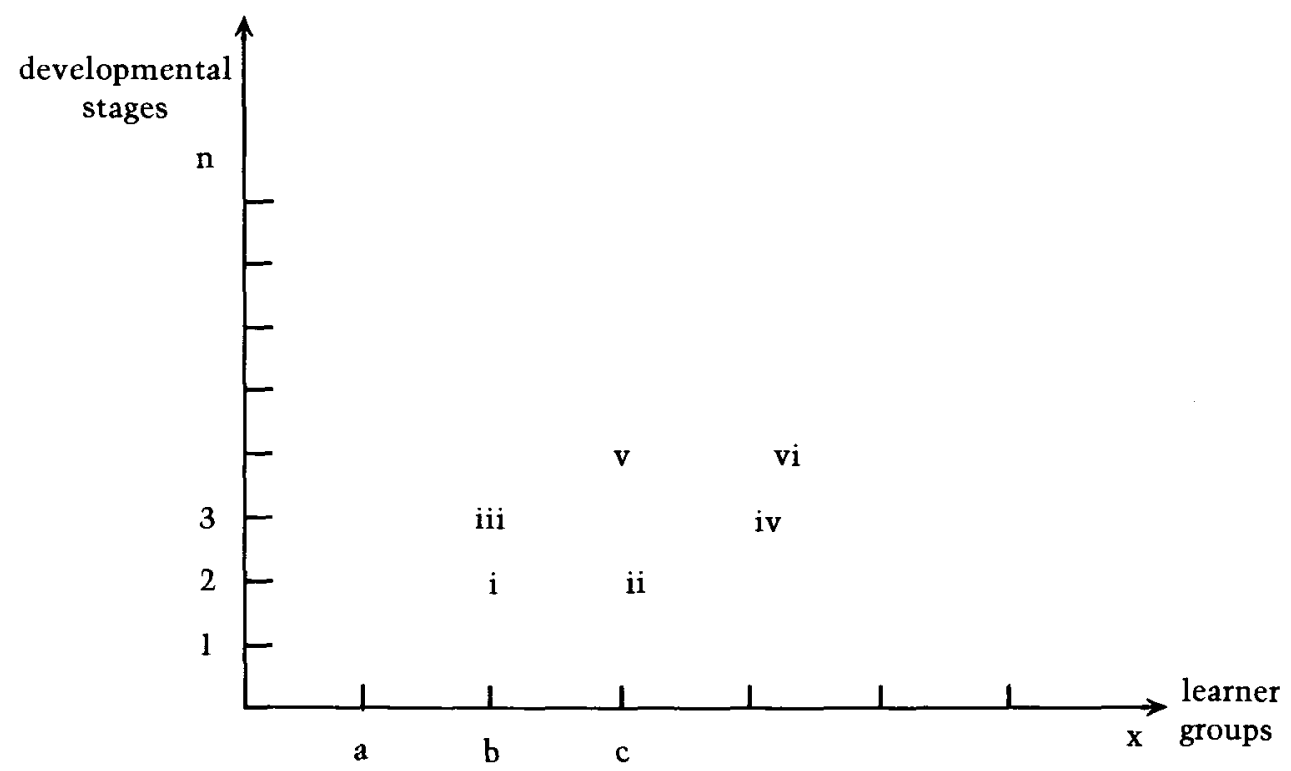

The different steps on the y-axis (vertical) represent different developmental stages, as defined by certain linguistic criteria. The points on the $\mathrm{x}$-axis (horizontal) indicate different learner groups, again in terms of linguistic criteria, such as the various kinds of simplification, etc. Note that the whole picture is based merely on linguistic facts. The reasons, however, why a learner is situated at a specific point in the diagram are mostly non-linguistic in nature. Socio-psychological factors play a very important role, as has been argued throughout this paper. Furthermore, indicating precise points on either axis is only possible as a result of a number of idealizations. A factor analysis may, for example, indicate the optimal set of factors for the definition of one learner group. A learner, however, need not meet all the conditions which together serve to define points $a, b, c \ldots x$. In this picture, development towards the target variety is represented as an approximation towards $\mathrm{n}$. The learner group (i.e. the ideal picture of this group) which only-or almost exclusively-uses standard-like constructions on all levels of development is represented by $x$. Those who use a 'pidginized' grammar are close to point a. Note that movement from a toward $x$ need not imply increasing complexity, nor is 3 necessarily a more complex stage than 1 . Although this may be the case, language acquisition is not always defined as an increasing number of rules. It may also mean that rules of the transitional grammar are abandoned and that strategies of simplification are given up. 
Finally, this figure should not be misunderstood as assigning a position to the learner once and for all. He/she obviously moves upward as he/she goes through developmental stages. But whether one belongs to one group or another may also change, especially if the socio-psychological factors change. A typical case might be that an immigrant has decided to make his fortune; he has a very positive attitude toward the new social environment. After two years, he may have learned that his expectations are not met economically and that the native population rejects him. What good can a perfect mastery of the language do him, then? As a result, his attitudes change as well as his motivation to learn the language. The opposite case can be illustrated by an immigrant who, after a few years, gets married to a native. In sum, one should not think of $L 2$ acquisition in this model as a steady movement in one direction; ups and downs are as likely as changes to the right or the left (in terms of the directions pictured in Figure 1).

As a further help toward understanding the meaning of this figure, the six learners mentioned in section 3.3. are tentatively located, mapping the results of tables (2) and (3) onto Figure 1. Numbers i-vi give the approximate position of Lolita $S$. (i), Angelina S. (ii), Franco I. (iii), Maria I. (iv), Benito I. (v), and Janni I. (vi).

\section{Possible applications of the model}

4.0. The principal goal of this paper was to contribute to a better understanding of the process of second language acquisition in a natural setting. We hope to have shown that certain properties of learners' interlanguages cannot be interpreted as marking steps in a developmental sequence. Rather, by taking a sociopsychological approach one may be able to explain some features as being the result of strategies which are not shared by all speakers, but are specific to only one or several groups of learners. Although characterized linguistically, these groups are mainly the result of different socio-psychological orientations.

If this is an adequate view of second language acquisition, it should not only help to clarify some notions of a theory of L2-acquisition but it should also be useful in designing adequate language classes for people who have lived for some time in the L2 environment before attending classes. This is the case for almost all immigrants in Germany. One of the major problems in such courses is that two acquisition processes have to be coordinated: natural L/2 acquisition up to the time when the classes start and also during the months of instruction-and language learning in the classroom. For this to be successful, the teacher has to find out what the learner already knows; otherwise the risk is that things are taught which are already familiar to the student. Such a procedure is not only inefficient and boring; adult students frequently get the feeling that what they have achieved by themselves is not taken seriously.

In this situation our proposal may be helpful for an evaluation of the learner's position: not only in terms of developmental stages but also with respect to learner groups. These two directions can be very important, for they may require different kinds of interventions on behalf of the teacher. Assuming that our model finds more empirical support, it should be possible to list a number of linguistic features 
for each developmental stage and for each group of learners. This will allow one to design placement tests to locate each individual's position in a diagram like that exemplified in Figure 1, and thus determine what sort of instruction is needed.

As for designing language courses, the proposed model may also be the basis for establishing a psychologically plausible sequencing of teaching material. At first glance, the nonlinearity of the acquisitional process would seem to preclude such an application of the model, because it allows for considerable variation within an acquisitional stage and consequently a number of different developments of L2acquisition. However, as shown above, certain linguistic structures are general features of specific acquisitional stages. The order of acquisition of these structures can be used for the sequencing of teaching material. This is primarily a didactic task, which includes e.g. a decision about whether one continues to demand correct speech in L2-courses or accepts interlingual deviations. To solve this problem it will be necessary to investigate the possibility of changing the natural order of acquisition by means of instruction.

All this may sound quite optimistic, but we believe we have demonstrated the value of trying it out. There is, however, one point where we are rather sceptical. If a learner is located-in terms of Figure 1 -close to point a, will it be possible to bring him closer to $\mathrm{x}$ ? In other words, can he be taught to abandon certain strategies of pidginization? On the basis of the assumptions made throughout this paper we have reasons to expect that this will be very difficult. We have argued that a person belongs to a given learner group because of socio-psychological factors which determine his/her orientation, attitudes and motivation. If this is correct, it seems to be fairly hopeless to expect that his/her linguistic behavior will change drastically as a result of language classes alone. As long as the social factors remain unchanged, we predict that although changes may occur in the speech of the learner during the lessons, the transfer of what has been learned to everyday communication will be extremely difficult. Only language programs which are paralleled by efforts toward social integration can possibly improve the current situation.

\section{Notes}

1. A first version of this paper was presented at the Scandinavian-German Symposium on Migrant Workers, Roskilde, Denmark, March 20-24, 1978. For more details about the language and some non-linguistic problems of immigrant workers in Germany see Meisel (1977).

2. This research group was established in 1974 in the Department of Linguistics and Literary Studies of the Gesamthochschule Wuppertal-Bergische Universität. The present paper is mainly a result of the discussions of this group during a 15 month research project supported by the Ministerium für Wissenschaft und Forschung des Landes NordrheinWestfalen. (Research grant, April 1st 1977-May 31st 1978). The members of our ZISA group have contributed much to this discussion and we want to acknowledge their contribution: W.-M. Ahnen, Gudrun Jaehnicke, Ulrike Keunecke and Ulrike Rohde whose names do not appear among the authors. The results of this cross-sectional study on the language and the language use and on the socio-psychological factors determining the process of second language acquisition by foreign workers will be published in 1979; Deutsch als Zweitsprache. Der Spracherwerb ausländischer Arbeiter. Tübingen: TBL 
Verlag Gunter Narr (In prep.). Currently the research group is working on a longitudinal study on the development of the process of second language acquisition by adults; this project should test the hypotheses which resulted from the above mentioned profile study. It is scheduled for a period of three years and is supported by a research grant of the Stiftung Volkswagenwerk. For a short description see Meisel, Pienemann, Thiel (1976).

3. For similar research on German compare: Felix (1976), (1977); Wode (1976); Molony (1977); Pienemann (1979).

4. This line of reasoning seems rather unconvincing to us. First of all, the arguments are weak; e.g. phonological identification of Spanish es and English it's, seems less plausible for German es ist although the same phenomenon appears in our data. Second, as shown in the first section of this paper, similar constructions in the source language and in the learner's interlanguage cannot automatically be explained as interference. Finally, all the other longitudinal studies mentioned above have shown that is-constructions tend to appear very early in natural second language acquisition. Alberto even uses am correctly in all obligatory contexts, with only one exception. Nevertheless, he was not credited with having acquired the copula since the number of obligatory contexts did not fulfill Brown's criterion!

5. We would maintain this position even if the criterion were somewhat modified. Cazden et al. (1975:42) and Schumann (1975), for example, make a difference between acquisition and appearance; the latter does not imply that an item is used "correctly" according to standard norms. They also reduced the required numbers:

to say that an auxiliary has appeared it must be supplied at least $80 \%$ of the time in three consecutive samples and in each sample there must be at least two instances of the particular auxiliary under consideration with a total of ten or more auxiliaries in the sample.

Leaving aside the fact that the figures required seem to be rather arbitrarily chosen, whereas those in Brown's criterion were motivated by his and by Cazden's (1968) findings, we are puzzled by this distinction which seems to say that only when a construction fulfills the norms of the standard variety one may claim that a rule has been acquired; features of what one might call an interim system, on the other hand, merely appear (without having been acquired?)!

6. Fathman (1979:30 f\}, for example, uses the terms 'order of acquisition' and 'number of mistakes' simply as synonyms. In what follows we do not want to give the impression that we are especially critical about Fathman's work. Quite to the contrary it still remains instructive and useful if interpreted in the way we will show in the next paragraph.

\section{References}

Bailey, C.-J. N. 1972 The practical value of abstract syntax for the ordinary working grammarian. Studies in language and linguistics, ed. by R. W. Ewton Jr. and J. Ornstein, 1-11. El Paso: Texas Western Press.

1976. The state of non-state linguistics. Annual Review of Anthropology 5.98-

106.

1977. Variation and linguistic analysis. Papiere zur Linguistik 12. 5-56.

C. Madden; and S. Krashen. 1974. Is there a 'natural sequence' in adult second language learning? Language Learning 24.235-43.

Bever, T. G. 1970. The cognitive basis for linguistic structures. Cognition and the development of language, ed. by J. R. Hayes, 279-362. New York: Wiley. 
Brown, R. 1973. A first language. The early stages. Cambridge, MA: Harvard University Press. Cazden, C. B. 1968. The acquisition of noun and verb inflections. Child Development 39.433-48.

Cazden, C.B., Cancino, H., Rosansky, E., and Schumann, J. H. 1975. Second language acquisition in children, adolescents, and adults. Cambridge, MA.

Clahsen, H. 1979. Syntax odex Produktionsstrategien? Zum natürlichen Zweitspracherwerb der 'Gastarbeiter.' Bildung und Ausbildung, ed. by R. Kloepfer et al., 343-54. Munich: Fink.

1980. Psycholinguistic aspects of L2 acquisition: word order phenomena in foreign worker's interlanguage. Second language development: Trends and issues, ed. by S. W. Felix, 57-79. Tübingen: Narr.

and J. M. Meisel, 1980. Eine psycholinguistische Rechtfertigung von Wortstellungsregeln im Deutschen. Papiere zur Linguistik 21.3-25.

Dulay, H. C., and M. K. Burt. 1973. Should we teach children syntax? Language Learning 23.245-258.

24.37-54.

.1974. Natural sequences in child second language acquisition. Language Learning

Fathman, A. K. 1979. Similarities and simplification in the interlanguage of second language learners. The notions of simplification, interlanguages and pidgins and their relation to second language pedagogy, ed. by S. P. Corder and E. Roulet, 30-8. Geneva: Droz.

Felix, S. W. 1976. Linguistische Untersuchungen zum englischdeutschen Zweitsprachenerwerb unter natürlichen Bedingungen. Arbeitspapiere zum Spracherwerb 18. Kiel.

1977. Interference, interlanguage, and related issues. In Molony, C. H., ed. 237-58.

(ed.) 1980. Second Language development. Trends and issues. Tübingen: Narr.

Gardner, R. C., and W. E. Lambert. 1972. Attitudes and motivation in second language learning. Rowley, MA.: Newbury House.

; P. C. Smythe; D. M. Kirby; and J. R. Bramwell. 1974. Second language acquisition: a social psychological approach. Final Report (Ontario Ministry of Education, Grant-in-Aid to Education), London, Ontario.

Haugen, E. 1956. Bilingualism in the Americas: a bibliography and research guide. (Publication of the American Dialect Society no. 28). University, Ala.: University of Alabama Press.

Heidelberger Forschungsprojekt 'Pidgin-Deutsch spanischer und italienischer Arbeiter in der Bundesrepublik' (HPD). 1976. Untersuchungen zur Erlernung des Deutschen durch ausländische Arbeiter. (Manuscript).

Hyltenstam, K. 1977. Implication patterns in interlanguage syntax variation. Language Learning 27.383-411.

Littlewood, W. T. 1975. The transmission of functional information and social information in learners' speech. Paper presented at AILA Congress 1975, Stuttgart.

Meisel, J. M. 1977. The language of foreign workers in Germany. Deutsch im Kontakt mit anderen Sprachen-German in contact with other languages, ed. by C. H. Molony, H. Zobl, and W. Stölting, 184-212. Kronberg, Ts.: Scriptor.

1980. Linguistic simplification: a study of immigrant workers' speech and foreigner talk. Second language development. Trends and issues, ed. by S. W. Felix, 13-40. Tübingen: Narr. 
, and M. Pam (eds.). 1979. Linear order and generative theory. Amsterdam: Benja-

mins.

M. Pienemann; and M. Thiel. 1976. The acquisition of German by foreign workers. Sociolinguistics Newsletter 7.9-10.

Molony, C. H. 1977. 'Ich bin sprechen Deutsch aber': the sequence of verb and word order acquisition of an American child learning German. Deutsch im Kontakt mit anderen Sprachen-German in contact with other languages. Kronberg; Ts.: Scriptor.

Osgood, C. E.; G. J. Suci; and P. H. Tannenbaum. 1957. The measurement of meaning. Urbana: University of Illinois Press.

Pam, M. D. 1979. Problems in the description of German word order. Linear order and generative theory, ed. by J. M. Meisel and M. Pam, 289-315. Amsterdam: Benjamins.

Pienemann, M. 1979a. Erwerbssequenzen und Lehrprogression Uberlegungen zur Steuerung des Zweitspracherwerbs; Bildung und Ausbildung in der Romania, ed. by R. Kloepfer et al., 398-416. Munich: Fink.

1979b. Der Zweitspracherwerb ausländischer Arbeiterkinder. Wuppertal University Dissertation.

Schumann, J. H. 1975. Second language acquisition: the pidginization hypothesis. Harvard University Dissertation.

1976. Social distance as a factor in second language acquisition. Paper presented at TESOL Convention, New York.

Stauble, A.-M. 1977. The process of decreolization: a model for second language development. Los Angeles: UCLA. (Manuscript).

Wode, H. 1976. Developmental sequences in naturalistic L2 acquisition. Arbeitspapiere zum Spracherwerb 12. Kiel. 